\title{
Influence of Students' Online Fragmented Learning on Learning Effect: The Mediating Effect of the Internet
}

\author{
https://doi.org/10.3991/ijet.v17i01.28471 \\ Yu Song ${ }^{1}$, Tao Huang ${ }^{1,2(\bowtie)}$ \\ ${ }^{1}$ Xichang University, Xichang, China \\ ${ }^{2}$ Goshen College, Indiana, USA \\ xcc03200023excc.edu.cn
}

\begin{abstract}
With the rapid development of information network technology, the world has entered a new era of $5 \mathrm{G}$ communication. The mobile internet is convenient and timeliness, making it convenient for students to conduct fragmented learning. The role of fragmented learning methods in students' classes has improved their autonomy in learning and application skills. Based on the view of constructivism knowledge, four factors of fragmented learning were proposed, which influences the learning effect, and the intermediary role of the Internet in fragmented learning on the learning effect was analyzed by using classical questionnaires. Results show that the overall Cronbach $\alpha$ of the questionnaire is 0.928 , which indicates that the questionnaire has good reliability; the KMO value of each influencing factor is 0.918 , which indicates that the questionnaire had good validity. The Internet has a partial mediating effect between the personal characteristics, learning motivation, and learning input of fragmented learning and the learning effect, and the effect of the personal characteristics is the strongest; the Internet has a masking effect on the influence of learning resources on learning effect. Conclusions are of great significance for discussing the influence of fragmented learning on college teaching under the background of "Internet+", integrating fragmented learning, and building the culture of fragmented learning by using the Internet.
\end{abstract}

Keywords — students, online fragmented learning, learning effect, mediating effect, masking effect

\section{Introduction}

With the popularization of mobile networks and intelligent terminals, online learning gradually gets rid of the restrictions of access through wired networks and fixed terminals, and truly realizes the state of learning anytime and anywhere. In the Internet age, the carrier of knowledge has changed from linear papers and books to hypertexts, videos, audios, and images, among other media. The knowledge dissemination is networked and hyperlinked, while the content of knowledge is also constantly flowing and evolving among learners. With the continuous update and development of information technology, smart phones, tablet computers, and other mobile terminals 
have become the necessities in the daily study of students. Students use these mobile terminals for fragmented learning.

With the rapid development of network media and the wide dissemination of network information, fragmented learning has become the trend of social development in the Internet era. The fragmentation not only affects all aspects of society, but also plays an important role in the pursuit of self-improvement and individuality of learners. In the era of mobile Internet, knowledge is more disorderly and scattered, wherein most Chinese learners expect to make full use of their spare time to learn fragmented knowledge efficiently. The traditional teaching is the main way to impart knowledge at present. However, with the development and progress of the time, we shall keep pace, thus adopting advanced teaching methods and information technology to combine traditional and systematic learning methods with networking and fragmented learning methods, integrating their advantages and promoting learners to learn efficiently. However, the mobility of learners and the dispersion of their attention may lead to the failure of mobile learners in conducting coherent and systematic learning. As the premise and foundation of flipped classrooms in reading and writing, fragmented learning is conducive to the knowledge transfer from classrooms to extracurricular activities. In scattered time and nonsystematic learning, how to ensure the effect of fragmented learning has become the key problem of this study.

\section{Theoretical background and research hypothesis}

\subsection{Theoretical background}

Constructivism was first proposed by J. Piaget, a Swiss psychologist. He believed that knowledge is the result of the gradual construction of the individual in the process of interacting with the environment. The teaching concept of constructivism is no longer regarded as the knowledge about absolute reality, but it is developing, and the knowledge has constructivity, sociality, contextuality and complexity, and so on. Studying is not the passive acceptance of knowledge, but the positive selection and processing of external information based on the original knowledge and experience of students, and the construction of their knowledge. The teachers should become active helpers and guides for students to construct knowledge, and to help students in constructing the meaning of current knowledge by creating scenes that fulfill the requirements of teaching content and determine the connection between old and new knowledge; the role of students is that of a participant in teaching activities and the builder of knowledge.

The fragmented learning is not limited by time and space in the era of "Internet+", which can be conducted anytime and anywhere, and there are various ways and means to acquire knowledge and information. The traditional teaching content is based on the teaching materials, with a complete knowledge system and rigorous logic system. The fragmentation of learning content can cut overall and systematic knowledge into points, and learners can choose to learn according to their personal needs and characteristics, which is conducive to the digestion and absorption of 
knowledge. Under the background of "Internet+", the channels of knowledge acquisition are becoming diversified. With the help of various mobile terminals, the students can learn fragmented knowledge through online micro-courses and MOOCs. With the rapid development of science and technology in today's society, the pace of life, study and work are fast, thus the fragmentation of learning content can satisfy people's impetuous psychology. Through the Internet, the learning space is no longer limited to offline learning in fixed classrooms, the students can choose online learning by using mobile phones, tablet computers, and other mobile terminals. With the help of the network platform, students have more flexible learning time and space, which greatly increases the opportunity for students to learn knowledge. In traditional college teaching, teachers make a systematic and complete teaching plan according to teaching objectives, then conduct teaching step by step, but it is for all students, and students can develop appropriate, clear, and specific fragmented learning plans according to their individual needs and circumstances. For example, they may make a study plan at a fixed time every day. They can read articles within half an hour after waking up every morning, and write their feelings or a summary of the articles read in the morning within ten minutes after soaking their feet in the evening. The fragmentation of study plans requires students to have good integration ability. Each fragment plan seems to be separate, but they are interrelated, complementary, and may expand mutually. Therefore, under the background of "Internet+", the contents of fragmented learning for students shall be designed according to the characteristics of students' fragmented learning and the analysis of students' learning conditions; thus, the students can make use of fragmented time to prepare lessons before class. Teachers, as thinking guides in the classroom, should give full play to the advantages of students' fragmented learning, integrate fragmented learning into the classroom teaching process of college reading and writing, guide students to develop their fragmented learning ability, and improve their skills in reading and writing, which can have a positive effect on their future study and work.

\subsection{Research hypothesis}

The relevant research on fragmented learning has been conducted earlier in foreign countries, and after years of development, progress has been made in theory and practice. The learning theory of constructivism believes that the learning process is an active construction of knowledge, and advocates "learner-centered" in the process of "regeneration" or "recreation" based on their existing knowledge. The process of fragmented learning is that learners can acquire resources conveniently from the Internet according to their own learning needs and interests and establish connections with existing knowledge to construct their meaning. The process is nonlinear and has the characteristics of fragmentation. Under the background of the Internet, fragmented learning is an active learning process, learners will consciously use the fragmented time to acquire knowledge and have strong learning autonomy; Secondly, in the process of fragmented learning, learners will acquire the knowledge they need in their studies, life or work in various situations or interactions to construct their knowledge system or improve their skills, as well as cultivate the ability and habit of autonomous 
learning; Lastly, the study of learners also presents the trend of individualism in the process of fragmented learning, the learning process has strong individualism due to the differences between individuals in terms of learning interest and learning content.

Eison et al. [1] classified the students according to their characteristics and studied the learning performance of different personal characteristics. Vicent-Morin et al. [2] studied and confirmed the relationship between students' learning choice and their characteristics. Bragt et al. [3] believed the personal characteristics of students have a certain impact on the learning effect. Blumenfeld et al. [4] considered the possible contribution of the learning view of constructivism to the goal theory.

H1: Internet can play an obvious mediating effect between personal characteristics and learning effect.

Pintrich [5] argued that the motivation of students must be fully developed in the teaching environment, thus highlighting three general themes of motivation research. Csizr et al. [6] thought that the motivation of language learning was a complex composite structure, and have adopted a structural equation model to evaluate the theoretical model of the internal structure of the second language motivation complex and its influence on motivational behavior. Harrington et al. [7] believed that input-driven models provided a clear and easy-to-test approach for language learning.

$\mathrm{H} 2$ : Internet can play an obvious mediating effect between learning motivation and learning effect.

Peters et al. [8] indicated that the vocabulary of learners and the frequency of an item appearing in a video clip are positively correlated with word learning. Webb [9] believed that expanding one's vocabulary through listening and context can promote our understanding of how vocabulary is learned. Richardson et al. [10] believed that academic records are an important fact affecting the effect of online learning. However, with more attention to the subjective intention of learners, it was found that learning motivation, learning experience, and other factors were also often used to show the effect of online learning. Rosário et al. [11] and other people showed that, through research, it has remarkable effects on the formation of effective learning strategies and the cultivation of self-regulation ability in the learning process of students that strengthens the self-management and learning method guidance of freshmen.

H3: Internet can play an obvious mediating effect between learning input and learning effect.

Manouselis et al. [12] stated that a rich knowledge base of online education resources could support the formation of online learning communities by providing a platform for collaboration. Lehmann et al. [13] believed that the learning resources experienced may be processed through creation, use, provision, or reuse in the entire life cycle of learning resources. Madden et al. [14] showed that most of the respondents were confident in their ability to use the Internet, among which the most confident users were young teachers in technical subjects, and the majority supported the Internet as a valuable source of learning and teaching materials.

H4: Internet can play an obvious mediating effect between learning resources and learning effect.

Based on the theory of constructivism, this paper proposed the students' characteristics, learning motivation, learning input, and learning resource ownership as the 
subjects of fragmented learning, which directly influenced the learning effect. Due to the assumptions, this paper proposed a research model, as shown in Figure 1.

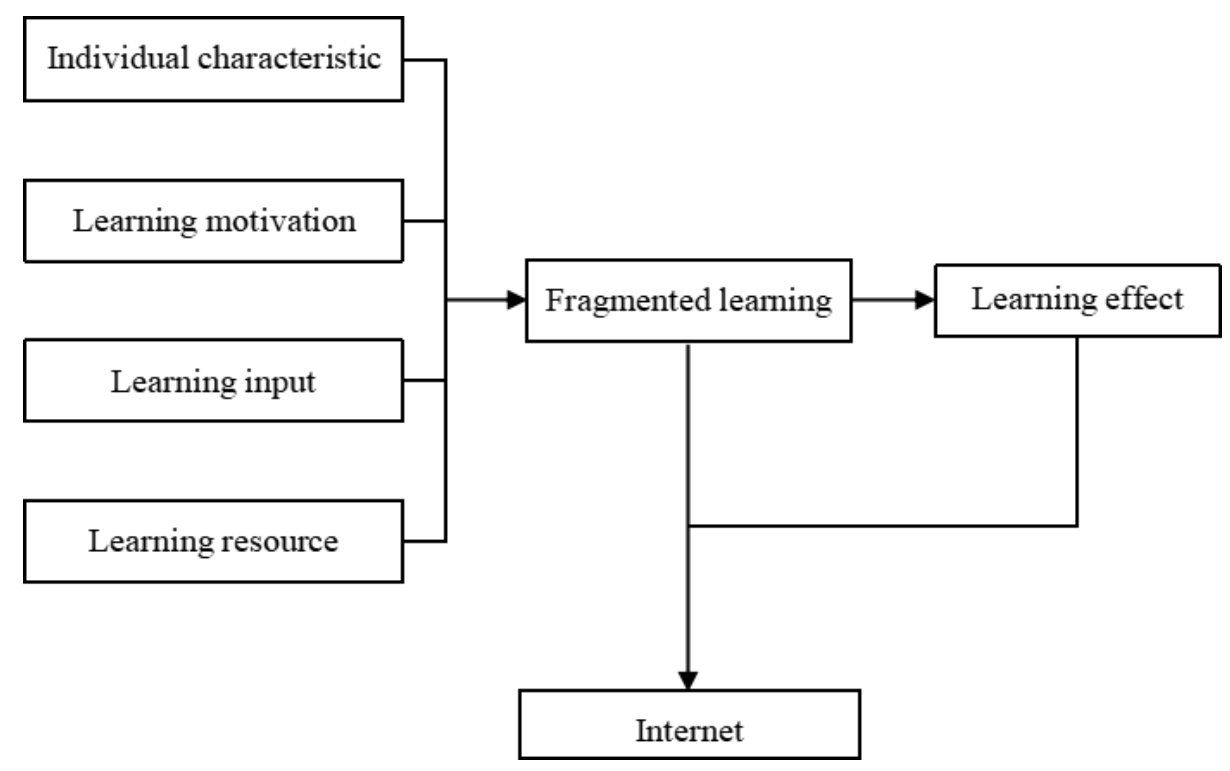

Fig. 1. Research and analysis model

\section{$3 \quad$ Research design}

\subsection{Measurement of variables}

Some studies have shown that the effect of fragmented learning on colleges was mainly influenced by four factors, such as personal characteristics, learning motivation, learning input, and learning resources. Based on the influencing factors identified by the previous studies, this study compiled "The influence of online fragmented learning of students on learning effect under the network background", modified and formed a questionnaire with 35 questions on the fragmented learning situations of students. The questionnaire is divided into three parts, the first part is the basic information, which included 4 questions; the second part is the influencing factor, which included 26 questions; and the third part is the learning effect, which included 5 questions. The questionnaire was measured by a Likert scale.

\subsection{Data collection}

This study used students as the research objects to investigate the informal, autonomous, and ubiquitous fragmented learning situations of students based on mobile multimedia devices. The official questionnaires were mainly distributed through the Wenjuanxing Platform and sent to undergraduates through QQ and WeChat. The 
respondents were mainly from Beijing, Sichuan, Guangdong, Inner Mongolia, Jiangsu, and other regions, which received 542 questionnaires, but only 389 questionnaires were collected, except for those questionnaires that did not meet the regulations and the answers were irrelevant to fragmented learning. It can be seen from Table 1 that the sample distribution ratio was relatively reasonable, which can reflect the fragmented learning effect of students. Therefore, the results of the survey were of certain reliability and typicality for understanding and analyzing the differences and influencing factors of fragmented learning effects of students.

Table 1. Basic information of respondents

\begin{tabular}{|l|c|c|c|}
\hline \multirow{3}{*}{ Sex } & & Number & Proportion \\
\hline \multirow{4}{*}{ Grade } & Male & 187 & $48.07 \%$ \\
\cline { 2 - 4 } & Female & 202 & $51.93 \%$ \\
\cline { 2 - 4 } & Freshman & 124 & $31.88 \%$ \\
\cline { 2 - 4 } & Sophomore & 101 & $25.96 \%$ \\
\cline { 2 - 4 } & Junior & 117 & $30.08 \%$ \\
\cline { 2 - 4 } Course & Senior & 47 & $12.08 \%$ \\
\cline { 2 - 4 } & Language and Literature & 142 & $36.50 \%$ \\
\cline { 2 - 4 } & Economics and Management & 136 & $34.96 \%$ \\
\hline
\end{tabular}

\section{$4 \quad$ Data analysis and result}

\subsection{Reliability and validity analysis}

The rationality of the questionnaire design can directly affect the authenticity and reliability of research results, a good questionnaire must have good validity and reliability. The reliability test is an important index to measure the reliability of data. In the research course, it was difficult to repeat two surveys of the same sample due to objective conditions. Therefore, researchers mainly adopted "a reliability coefficient method"; namely, the Cronbach reliability coefficient, to test the reliability of data containing the Likert Scale. Generally, the higher $\alpha$ value is, the higher the reliability of the questionnaire. The reliability coefficient should be acceptable when it reaches 0.8 in the process of basic research, and 0.7 only in the process of exploratory research.

It can be seen from Table 2 that the reliability coefficients were $0.815,0.783$, $0.834,0.826,0.903,0.956$, and 0.834 , which were more than 0.7 , indicating that the reliability quality of research data is relatively high. For "deleted $\alpha$ coefficient" and "CITC value", the CITC values were more than 0.4 , which indicated that a good correlation exists between the analysis items and good reliability level. 
Table 2. Cronbach Reliability Analysis

\begin{tabular}{|l|c|c|c|}
\hline \multicolumn{1}{|c|}{ Name } & Calibration items of total correlation (CITC) & $\boldsymbol{\alpha}$ & Cronbach $\boldsymbol{\alpha}$ \\
\hline AA1 & 0.629 & 0.925 & 0.926 \\
\hline AA2 & 0.508 & 0.925 \\
\hline AA3 & 0.573 & 0.925 \\
\hline AA4 & 0.639 & 0.927 \\
\hline AB1 & 0.477 & 0.926 \\
\hline AB2 & 0.507 & 0.926 \\
\hline AB3 & 0.544 & 0.926 \\
\hline AB4 & 0.502 & 0.924 \\
\hline AC1 & 0.683 & 0.925 \\
\hline AC2 & 0.613 & 0.924 \\
\hline AC3 & 0.666 & 0.926 \\
\hline AD1 & 0.545 & 0.924 \\
\hline AD2 & 0.638 & 0.924 \\
\hline AD3 & 0.671 & 0.928 \\
\hline BA1 & 0.492 & 0.929 \\
\hline BA2 & 0.414 & 0.928 \\
\hline BA3 & 0.462 & 0.928 \\
\hline BA4 & 0.442 & 0.927 \\
\hline BA5 & 0.400 & 0.929 \\
\hline BA6 & 0.496 & 0.928 \\
\hline BA7 & 0.405 & 0.928 \\
\hline BA8 & 0.470 & 0.924 \\
\hline BB1 & 0.664 & 0.924 \\
\hline BB2 & 0.674 & 0.924 \\
\hline BB3 & 0.678 & 0.924 \\
\hline BB4 & 0.688 & 0.926 \\
\hline C1 & 0.501 & 0.926 \\
\hline C2 & 0.510 & 0.926 \\
\hline C3 & 0.507 & 0.926 \\
\hline C4 & 0.494 & 0.926 \\
\hline C5 & 0.540 & \\
\hline & & \\
\hline & & 0.928 \\
\hline
\end{tabular}

The validity test would test whether the survey tools could accurately provide feedback on the degree of the target characteristics of the object to be measured. Generally, the more consistent the measurement results and the survey content, the higher the validity; on the contrary, the lower the validity. This study tested the construction validity of the questionnaire through exploratory factor analysis, in which the KMO should be above 0.6 and the conjoint probability corresponding to Bartlett's test of sphericity should be less than 0.05 , which indicated that common factors exist in the overall correlation matrix, and was suitable for factor analysis. The KMO value of each influencing factor sampled in this study was 0.918 , and the chi-square value of 
Bartlett's spherical test was $7029.488(P=0.000<0.05)$, which indicated that there were common factors in the overall correlation matrix, and was suitable for factor analysis. Therefore, the questionnaire has good construction validity.

Table 3. KMO and Bartlett

\begin{tabular}{|l|c|c|}
\hline KMO & Approximate chi-square & 0.918 \\
\hline \multirow{3}{*}{ Bartlett's Test of Sphericity } & df & 7029.488 \\
\cline { 2 - 3 } & p value & 465 \\
\cline { 2 - 3 } & & 0.000 \\
\hline
\end{tabular}

\subsection{Mediating effect}

It can be seen from Table 4 that three models are involved in the analysis of mediating effect.

1. Learning effect $=-0.000+0.316 *$ individual character $+0.219 *$ learning motivation $-0.075 *$ learning input $+0.244 *$ learning resources.

2. Internet $=-0.000+0.308 *$ individual character $+0.177 *$ learning motivation + $0.202 *$ learning input $+0.174 *$ learning resource.

3. Learning effect $=-0.000+0.223 *$ individual character $+0.165 *$ learning motivation $-0.137 *$ learning input $+0.191 *$ learning resource $+0.304 *$ internet.

Table 4. Result of mediating effect

\begin{tabular}{|l|c|c|c|}
\hline & Learning effect & Internet & Learning effect \\
\hline \multirow{2}{*}{ Constant } & -0.000 & -0.000 & -0.000 \\
& $(-0.000)$ & $(-0.000)$ & $(-0.000)$ \\
\hline \multirow{2}{*}{ Individual character } & $0.316^{* *}$ & $0.308^{* *}$ & $0.223^{* *}$ \\
& $(5.861)$ & $(6.589)$ & $(4.050)$ \\
\hline \multirow{2}{*}{ Learning motivation } & $0.219^{* *}$ & $0.177^{* *}$ & $0.165^{* *}$ \\
& $(4.112)$ & $(3.837)$ & $-0.152)$ \\
\hline \multirow{2}{*}{ Learning resource } & -0.075 & $0.202^{* *}$ & $(-2.079)$ \\
\hline \multirow{2}{*}{ Learning input } & $(-1.123)$ & $(3.489)$ & $0.191^{* *}$ \\
& $0.244^{* *}$ & $0.174^{* *}$ & $(3.292)$ \\
\hline \multirow{2}{*}{ Internet } & $(4.122)$ & $(3.399)$ & $0.304^{* *}$ \\
& - & - & $3.335)$ \\
\hline Sample size & 389 & 389 & 0.386 \\
\hline$R^{2}$ & 0.341 & 0.506 & 0.378 \\
\hline Adjust $R^{2}$ & 0.334 & 0.501 & $F(5,383)=48.186$, \\
\hline \multirow{2}{*}{$F$ value } & $F(4,384)=49.572$, & $F(4,384)=98.287$, & $\mathrm{p}=0.000$ \\
\hline
\end{tabular}

Note: Figures in brackets is $t$-value.

${ }^{*} p<0.05$

${ }^{* *} p<0.01$ 
It can be seen from Table 5 that the Internet has a significant mediating effect on the fragmented learning effect of students, proving the following hypotheses in this study.

Table 5. Result of mediating effect size

\begin{tabular}{|l|c|c|c|c|c|}
\hline \multicolumn{1}{|c|}{ Item } & Result & $\begin{array}{c}\text { Total } \\
\text { effect }\end{array}$ & $\begin{array}{c}\text { Mediating } \\
\text { effect }\end{array}$ & $\begin{array}{c}\text { Direct } \\
\text { effect }\end{array}$ & Proportion \\
\hline $\begin{array}{l}\text { Individual character=>Internet=> } \\
\text { Learning effect }\end{array}$ & $\begin{array}{c}\text { Partial mediating } \\
\text { effect }\end{array}$ & 0.316 & 0.094 & 0.223 & $29.568 \%$ \\
\hline $\begin{array}{l}\text { Learning motivation=> Internet => } \\
\text { Learning effect }\end{array}$ & $\begin{array}{c}\text { Partial mediating } \\
\text { effect }\end{array}$ & 0.219 & 0.054 & 0.165 & $24.539 \%$ \\
\hline $\begin{array}{l}\text { Learning resource=> Internet => } \\
\text { Learning effect }\end{array}$ & Masking effect & -0.075 & 0.061 & -0.137 & $44.972 \%$ \\
\hline $\begin{array}{l}\text { Learning input=> Internet => Learn- } \\
\text { ing effect }\end{array}$ & $\begin{array}{c}\text { Partial mediating } \\
\text { effect }\end{array}$ & 0.244 & 0.053 & 0.191 & $21.688 \%$ \\
\hline
\end{tabular}

This study verified that the Internet had a partial mediating effect of personal characteristics on the learning effect. The main reason was that the internet classroom was different from the traditional classroom under the background of "Internet+". The Internet classroom overturned the dominant position of teachers and took students as the center in the teaching process. The fragmented learning would free students learning from being limited by time and space, and there are rich teaching resources with a wider range of choices. Under the background of "Internet+", fragmented learning would let students' complete reading [15], writing, and translation work, which originally occupied most of the classroom time before class in fragmented time, and students could have profound thinking on the learning content in the classroom under the guidance of teachers. The perfect combination of such teaching mode and Internet classroom enabled students to give full play to their subjective initiative, place more attention to cultivating students' independent learning ability after class, and focus on students' initiative and dominant position in the learning process. Students could use the fragmented time before and after class to remember, understand, and apply the content, and analyze, evaluate, and create in classroom time. In this way, students could adjust their learning progress according to their actual situation and study plan, as well as arrange their learning time and choose their learning place freely, which fully satisfied the requirements of personalized learning of students under the background of "Internet+".

This study verified that the Internet had a partial mediating effect of learning motivation on learning results. Under the background of the Internet, the motivation of learning mainly comes from two aspects. On the one hand, the arrangement, activity design, tasks, teaching methods, and teachers' charm will affect the fluctuation of students' motivation. On the other hand, students can use the Internet to make preparations before class, complete class tasks, and cooperate with classmates anytime and anywhere. Under the background of the Internet, the immediate thoughts, accompanied actions, emotions, behaviors, moods, and roles of students and teachers will affect the fluctuation of students' learning motivation, especially under the condition that the Internet is gradually mature, the stable signal in the classroom and compre- 
hensive popularization of mobile Internet devices will keep the motivation of learning and promote the occurrence of information-based classroom learning [16].

This study verified that the Internet had a masking effect of learning resources on learning effect. It can be seen that rich online learning resources exist under the background of the Internet [17], but there were plenty of outdated, inferior, incomplete, and inaccurate learning resources on the Internet. Many resources on the Internet are fragmented and may lack systems and logic, making it difficult for students to construct a body of systematized knowledge. The traditional online courses are having a difficult time in fulfilling the miniaturization, fragmentation, and personalized learning needs of learners due to the excessively large particle size and longtime learning resources, and the excessively large particle size is not conducive to timely updates and the update cost is high. Faced with the complex Internet environment, students, as the subjects of learning, may exceed their tolerance threshold due to the effect of excessive learning resources, may lead to the imbalance of learning effect, and cause the decline of their academic level.

This study proved that the Internet had a partial mediating effect of the learning input on learning effect. During the process of Internet teaching, teachers should actively create opportunities for interaction and cooperation between teachers and students, which can greatly stimulate the learning input of students; for example, arranged communication and discussion links and group cooperation tasks, to help students establish emotional bonds in the process of expressing opinions, obtaining feedback, sharing materials and collaborative learning, reduce students' negative emotional experiences caused by social isolation, such as loneliness and boredom, and so on. Meanwhile, teachers should encourage students to have the courage to ask questions and timely answer questions amid the confusion of students, provide feedback on effectiveness according to the learning dynamics of students and pay close attention to the emotional experience of students, strengthen the emotional support for students, conduct psychological counseling for bad mood of students, and improve the emotion input of students to the online course during the process of friendly interaction between teachers and students.

\section{Conclusion}

Under the background of the "Internet+", it has become an important way for contemporary students to conduct fragmented learning on mobile terminals using scattered and fragmented time. Integrating fragmented learning into the class-room teaching process of reading and writing classes, guiding students to develop fragmented learning ability to improve the overall learning effect of students' skills in reading, writing, and translation. The complete combination of information communication technology and teaching has a certain role in improving the knowledge level and teaching quality of students. This study proposed four factors wherein fragmented learning may affect learning effect, thus adopting a classical questionnaire to analyze the mediating effect of the Internet on fragmented learning and learning effect. 
The conclusions are as follows: (1) the overall Cronbach $\alpha$ was 0.928 , which indicated that the questionnaire had good reliability; the KMO value of each influencing factor was 0.918 , which indicated that the questionnaire had good reliability. (2) The Internet has a partial mediating effect between the personal characteristics, learning motivation, learning input of fragmented learning, and the learning effect. (3) The Internet has a masking effect of learning resources on learning effect.

The largest inspiration of the results was that the fragmented online teaching process shall fully consider individual characteristics in the context of the Internet, stimulate learning motivation, increase learning input, and do not simply pursue the quantity of learning resources, but fully consider the use of high-quality online learning resources.

\section{Acknowledgment}

This study was supported by the Department of Higher Education of MOE of China (No. 201902031025).

\section{$7 \quad$ References}

[1] Eison, J. A., Pollio, H. R., Milton, O. (1986). Educational and personal characteristics of four different types of learning-and grade-oriented students. Contemporary Educational Psychology, 11(1), 54-67. https://doi.org/10.1016/0361-476X(86)90012-3

[2] Vincent-Morin, M., Lafont, L. (2005). Learning-method choices and personal characteristics in solving a physical education problem. Journal of Teaching in Physical Education, 24(3), 226-242. https://doi.org/10.1123/jtpe.24.3.226

[3] Bragt, C., Bakx, A., Bergen, T., Croon, M. A. (2011). Looking for students' personal characteristics predicting study outcome. Higher Education, 61(1), 59-75. https://doi.org/10. 1007/s10734-010-9325-7

[4] Blumenfeld, P. C. (1992). Classroom learning and motivation: clarifying and expanding goal theory. Journal of Educational Psychology, 84(3), 272-281. https://doi.apa.org/doi/10. $1037 / 0022-0663.84 .3 .272$

[5] Pintrich, P. R. (2003). A motivational science perspective on the role of student motivation in learning and teaching contexts. Journal of educational Psychology, 95(4), 667-668. https://doi.apa.org/doi/10.1037/0022-0663.95.4.667

[6] Csizr, K., Drnyei, Z. (2005). The internal structure of language learning motivation and its relationship with language choice and learning effort. The Modern Language Journal, 89(1), 19-36. https://doi.org/10.1111/j.0026-7902.2005.00263.x

[7] Harrington, M., Dennis, S. (2002). Input-driven language learning. Studies in Second Language Acquisition, 24(02), 261-268. https://doi.org/10.1017/S0272263102002103

[8] Peters, E., Heynen, E., E Puimège. (2016). Learning vocabulary through audiovisual input: the differential effect of 11 subtitles and captions. System, 63, 134-148. https://doi.org/10. 1016/j.system.2016.10.002

[9] Webb, S. (2016). Learning vocabulary through meaning-focused input: Replication of Elley (1989) and Liu \& Nation (1985). Language Teaching, 49(1), 129-140. https://doi.org/ 10.1017/S0261444815000051 
[10] Richardson, J. C., Maeda, Y., Lv, J., Caskurlu, S. (2017). Social presence in relation to students' satisfaction and learning in the online environment: A meta-analysis. Computers in Human Behavior, 71, 402-417. https://doi.org/10.1016/j.chb.2017.02.001

[11] Rosário, P., Núñez, J. C., González-Pienda, J., Valle, A., Trigo, L., C Guimarães. (2010). Enhancing self-regulation and approaches to learning in first-year students: a narrativebased programme assessed in the Iberian Peninsula. European Journal of Psychology of Education, 25(4): 411-428. https://doi.org/10.1007/s10212-010-0020-y

[12] Manouselis, N., Vuorikari, R., Assche, F. V. (2010). Collaborative recommendation of elearning resources: an experimental investigation. Journal of Computer Assisted Learning, 26(4), 227-242. https://doi.org/10.1111/j.1365-2729.2010.00362.x

[13] Lehmann, L., Hildebrandt, T., Rensing, C., Steinmetz, R. (2008). Capture, management, and utilization of lifecycle information for learning resources. IEEE Transactions on Learning Technologies, 1(1), 75-87. https://doi.org/10.1109/TLT.2008.9

[14] Madden, A., Ford, N., Miller, D., Levy, P. (2005). Using the internet in teaching: the views of practitioners (a survey of the views of secondary school teachers in Sheffield, UK). British Journal of Educational Technology, 36(2), 255-280. https://doi.org/10.1111/j.14678535.2005.00456.x

[15] Nasir, N. A. M., Hashim, H., Rashid, S. M. M., Yunus, M. M. (2021). Exploring the Potential Usage of Mobile Technologies among the Hearing-Impaired Students in Learning English as a Second Language (ESL). International Journal of Interactive Mobile Technologies, 15(19), 48-63.

[16] Sulisworo, D., Yunita, L., Komalasari, A. (2017). Which mobile learning is more suitable on physics learning in indonesian high school?. International Journal of Recent Contributions from Engineering, Science \& IT (iJES), 5(1), 97-104. https://doi.org/10.3991/ijes. v5i1.6494

[17] Bergdahl, N., Nouri, J., Karunaratne, T., Afzaal, M., Saqr, M. (2020). Learning Analytics for Blended Learning: A Systematic Review of Theory, Methodology, and Ethical Considerations. International Journal of Learning Analytics and Artificial Intelligence for Education, 2(2), 46-79. https://doi.org/10.3991/ijai.v2i2.17887

\section{Authors}

Yu Song, Master of Arts, is a lecturer at School of Foreign Language Studies, Xichang University. Her research interests focus on language teaching and translation (Email: sophydm@126.com).

Tao Huang, Bachelor of Arts, is a professor at School of Foreign Language Studies, Xichang University and a visiting scholar at Goshen College. His research interests focus on language teaching and language testing.

Article submitted 2021-11-12. Resubmitted 2021-12-03. Final acceptance 2021-12-05. Final version published as submitted by the authors. 